\title{
Impact of a chest support on lower back muscles activity during forward bending
}

\author{
Armaĝan Albayrak ${ }^{\mathrm{a}, \mathrm{b} *}$, Richard H.M. Goossens ${ }^{\mathrm{a}}$, Chris J. Snijders ${ }^{\mathrm{a}, \mathrm{c}}$, Huib de Ridder ${ }^{\mathrm{a}}$ and Geert Kazemier ${ }^{\mathrm{b}}$ \\ ${ }^{a}$ Faculty of Industrial Design Engineering, Delft University of Technology, Landbergstraat 15, 2628 CE Delft, The Netherlands; \\ ${ }^{b}$ Department of Surgery, Erasmus Medical Centre of Rotterdam, Dr. Molewaterplein 40, 3015 GD Rotterdam, The Netherlands; \\ ${ }^{c}$ Department of Biomedical Physics and Technology, Erasmus Medical Centre of Rotterdam, Dr. Molewaterplein 40, 3015 GE \\ Rotterdam, The Netherlands
}

(Received 10 July 2008; final version received 9 December 2009)

\begin{abstract}
The present study is based on previous research on the poor body posture of surgeons and their experienced discomfort during surgical procedures. Since surgeons have head-bent and back-bent posture during open surgical procedures, a chest support is a viable supporting principle. This support is meant to reduce lower back pain by minimising lower back muscle activity. The aim of this study is to investigate the impact of a chest support on lower back muscle activity during forward bending and to establish a possible relation between supporting force and the kind of balancing strategy a person adopts. Use of the chest support shows a significant reduction of muscle activity in the lower back and leg muscles. Within the participants three user groups are identified as "sceptical users", "non-trusters" and "fully trusters", each following a different balancing strategy. Since there are different kinds of users, the designed body support should offer the possibility for altering the posture and should not constrain the user to take a certain body posture.
\end{abstract}

Keywords: biomechanics; electromyography; chest support; balancing strategy

\section{Introduction}

During surgical procedures, due to work related circumstances such as positioning the patient on the operating table and/or equipment in the operating room, surgeons have an ergonomically poor body posture - head-bent and back-bent posture. Besides surgeons there are many other professions contend with similar problems due to their poor body posture. Dentists, fruit or flower pickers and garage mechanics, for example, have a comparable head-bent and back-bent posture. Rohlmann et al. (2001) indicate that the load on the trunk is significantly increased during flexion of the upper body. During flexion of the upper body while standing, the pressure in the disc increased almost to $216 \%$ (the intradiscal pressure was $0.50 \mathrm{MPa}$ on average for standing) (Rohlmann et al. 2001). Such a posture leads to enhanced muscle activity to keep the upper body in balance (Albayrak et al. 2006a). This may be regarded as one of the main causes for physical complaints in the lower back during and after open surgical procedures.

Recently, Albayrak et al. (2007) proposed a new design for an ergonomic body support for surgeons that can be used during open as well as minimally invasive procedures. An important element in this design is a chest support meant to reduce lower back pain by reducing the lower back muscles, activity. The choice of a chest support as a supporting principle was made after a biomechanical analysis of the upper body.
This biomechanical model (see section Materials and Methods) appears to predict the conditions within subjects correctly but has some limitations in predicting the observed differences in muscle activity between subjects. Surprisingly, the measured muscle activity seems to decrease with increasing body length and weight (and hence muscle force) for females as well as males. Interestingly, similar deviations of biomechanical modelling have been reported by others (Granata and Marras 1995; Arjmand and ShiraziAdl 2005, 2006). As a possible explanation, Granata and Marras (1995) suggested that appropriate representation of muscle area is essential to the validity and performance of biomechanical models, because muscle force per unit area is highly variable between subjects, depending on participant condition and natural ability. Arjmand and Shirazi-Adl (2005) noted that in biomechanical models of trunk load, the balance of net external moments is considered only at one cross-section rather than along the entire length of the spine. Moreover, the evaluated muscle forces, once applied on the system along with external loads, may not necessarily generate the same spinal kinematics under which they were initially calculated (Arjmand and Shirazi-Adl 2005) Hence, due to their static and two-dimensional approach, biomechanical models seem to have some limitations in predicting conditions between subjects. Nevertheless, biomechanical models are useful for predicting conditions within subjects.

*Corresponding author. Email: a.albayrak@tudelft.nl

ISSN: 1176-2322 print/ 1754-2103 online

Copyright (C) 2010 Taylor \& Francis

DOI: 10.1080/11762320903541453

http://www.informaworld.com 

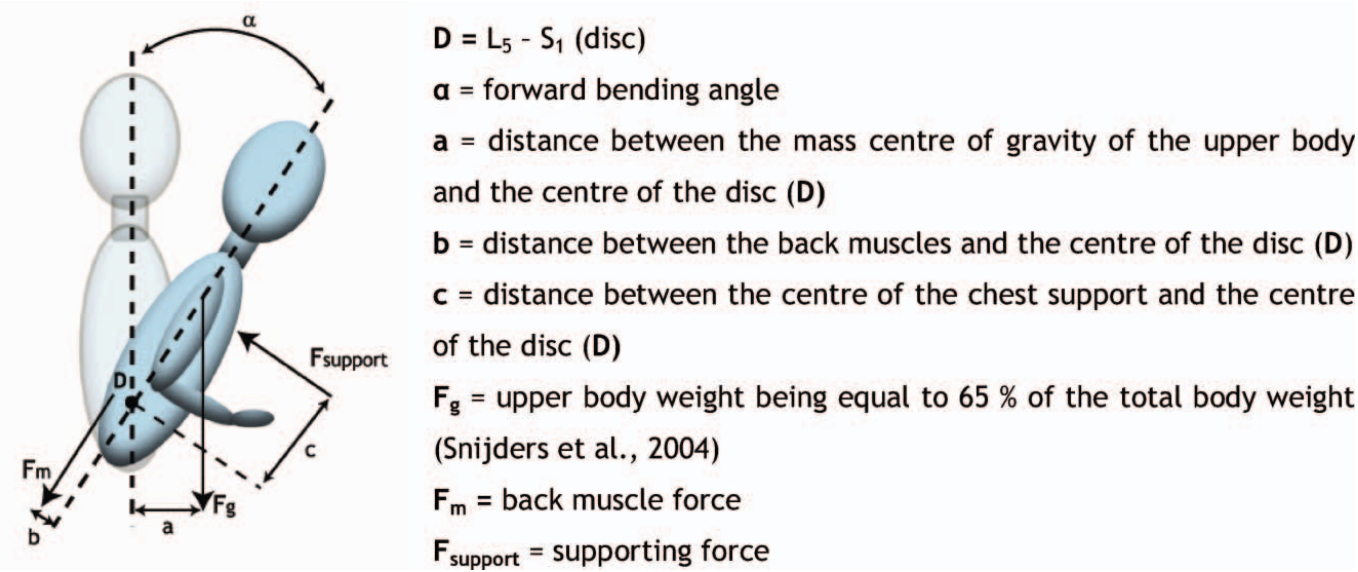

Figure 1. Biomechanical model of bending forward while leaning on a chest support. The reaction forces $\left(\mathrm{F}_{\mathrm{rg}}, \mathrm{F}_{\mathrm{rm}}\right.$ and $\left.\mathrm{F}_{\mathrm{rs}}\right)$ in the disc are not drawn in this model.

Next to the differences in muscle activity between subjects, humans tend to follow different balancing strategies during a standing posture. Winter (1995) describes three strategies (ankle, hip and combined) in relation to displacement of the centre of mass (COM) in an inverted pendulum model of balance in the anteroposterior $(\mathrm{A} / \mathrm{P})$ direction. The ankle strategy applies in quiet stance and during small perturbations and predicts that the ankle plantar flexors/dorsi flexors alone act to control the inverted pendulum. In more perturbed situations or when the ankle muscles cannot act, a hip strategy would respond to flex the hip, thus moving COM posteriorly, or to extend the hip to move the COM anteriorly. Using a computer simulation the displacement of the COM at each of these strategies was measured. A $10 \mathrm{~N} \mathrm{~m}$ ankle moment was applied for $300 \mathrm{~ms}$. The total body COM displacement (posterior) was estimated to be $1.56 \mathrm{~cm}$. The same $10 \mathrm{~N} \mathrm{~m}$ was applied as hip flexors to stimulate a hip strategy and the posterior displacement of the COM was $2.04 \mathrm{~cm}$. However, a combined ankle and hip strategy was quite possible and with a $10-\mathrm{N}$ m plantar flexor moment plus a 10-N m hip flexor moment the COM displaced $3.53 \mathrm{~cm}$ after $300 \mathrm{~ms}$ (Winter 1995).

To evaluate the conditions between and within subjects, a similar experimental set-up was used as in Albayrak et al. (2006a, 2007). The maximum angle was raised from $20^{\circ}$ to $40^{\circ}$. Additionally, the number of participants was increased such that the total range of body lengths was extended substantially. Finally, the number of muscles on which electromyography (EMG recording) was performed was increased to five: two muscles in the lower back, one in the abdomen and two in the right leg. This was done since there are indications that humans tend to follow different balancing strategies during a standing posture (Winter 1995). We assume that the different balancing strategies will be reflected in the pattern of EMG recordings from measured muscles. The aim of the present study is to investigate how subjects make use of a chest support in a general and on an individual level and to study the influence of the chest support on the muscle activity during bending forward. In this way a possible relation between the supporting forceand the kind of balancing strategy a person adopts in the current set-up might be established.

\section{Materials and methods}

\section{Biomechanical model}

For the analysis of the load transfer at the lumbar level, a free body diagram is made (Albayrak et al. 2006a, 2006b). Figure 1 shows the details of such a model for bending forward while leaning against a chest support. The upper body weight $\left(\mathbf{F}_{\mathbf{g}}\right)$, the back muscle force $\left(\mathbf{F}_{\mathbf{m}}\right)$ at the level of $\mathrm{L}_{5}$ (lumbar) and the supporting force $\left(\mathbf{F}_{\text {support }}\right)$ are included in this biomechanical model. Note that the model is limited to the sagittal plane and describes a static equilibrium. A cross-section of the trunk is made at $\mathrm{L}_{5}-\mathrm{S}_{1}(\mathrm{disc})$. The mass centre of gravity of the upper body is located near the arm pits (Snijders et al. 2004).

Considering the equilibrium of moment of forces in the sagittal plane at position $\mathbf{D}$, lower back muscle force $\mathbf{F}_{\mathbf{m}}$ can be calculated as follows:

$$
\begin{aligned}
& \text { Without Support }\left(\mathbf{F}_{\text {support }}=0\right) \\
& \mathbf{F}_{\mathbf{m}}=\mathbf{F}_{\mathbf{g}} \cdot(\mathbf{a} / \mathbf{b}) \\
& \text { With Support }\left(\mathbf{F}_{\text {support }} \neq 0\right) \\
& \mathbf{F}_{\mathbf{m}}=\mathbf{F}_{\mathbf{g}} \cdot(\mathbf{a} / \mathbf{b})-\mathbf{F}_{\text {support }} \cdot(\mathbf{c} / \mathbf{d}) .
\end{aligned}
$$

According to Equation (2) a head support might be considered most effective in reducing the muscle force in lower back since distance $\mathbf{c}$ is maximal (and thus maximises the factor $\left.\mathbf{F}_{\text {support }} \cdot(\mathrm{c} / \mathrm{b})\right)$. However, a head support is not desirable, since the freedom of movements of the surgeon will reduce dramatically. Furthermore, it will introduce an extra load on the neck. Nevertheless, the upper body should be 
supported as high as possible. Supporting the upper body at chest height (sternum) is a viable option, since the surrounding tissues mainly have a soft structure. A pressure on the soft tissue due to the supporting force will not be experienced as comfortable.

\section{Study I}

To investigate the viability of the chest support, a prototype was built and tested with five participants (Albayrak et al. 2006a, 2006b). The participants were three Dutch females $\left(\mathrm{P}_{5}, \mathrm{P}_{50}, \mathrm{P}_{95}\right.$-woman $)$ and two Dutch males $\left(\mathrm{P}_{50}, \mathrm{P}_{95}\right.$-man, percentiles Dutch population (Molenbroek 2004)). The experimental conditions consisted of two bending angles and two different heights of the support, both within the area of the chest. The posture of the participants simulated typical head- and back-bent posture of surgeons during surgical procedures. The muscle activity (electromyography, EMG recording) in the lower back (right side of $\mathrm{m}$. erector spinae) and right leg ( $\mathrm{m}$. gastrocnemius and $\mathrm{m}$. semitendinosus) was measured both with and without using the chest support. The results averaged across the participants showed that muscle activity increases proportionally with the bending angle during bending forward without chest support. The usage of the chest support reduced the muscle activity significantly with a major impact on the leg muscles. This reduction was found to depend on the height of the chest support but the resulting $\mathbf{F}_{\mathbf{m}}$ appeared almost independent of the bending angle. According to our biomechanical model the latter would imply that $\mathbf{F}_{\text {support }}$ is growing proportionally with bending angle $\boldsymbol{\alpha}$.

Following Kumar and Mital (1996) we assume a linear relationship between muscle force and muscle activity. The experimental results of the above study are qualitatively in agreement with our biomechanical model predictions for the lower back muscles (Equations (1) and (2)), since (1) muscle force, $\mathbf{F}_{\mathbf{m}}$, and thus muscle activity, increases with bending angle (or distance $\mathbf{a}$ ) in the condition without support and (2) muscle force, $\mathbf{F}_{\mathbf{m}}$, decreases when $\mathbf{F}_{\text {support }}$ is larger than zero. This effect is strengthened by increasing height (c) of the chest support.
These conclusions hold for results averaged across subjects. But the question rose what happens at the individual level? The model in fact incorporates two important anthropometric variables, namely body length in parameters $\mathbf{a}$ and $\mathbf{c}$ and body weight in parameter $\mathbf{F}_{\mathbf{g}}$. Hence, at individual level an additional prediction can be formulated, namely, muscle activity increases with body length and weight.

To assess the value of the biomechanical model at an individual level a comparison was made between calculated muscle force and measured muscle activity (EMG recording) in the lower back during bending forward without support. By using the first equilibrium of moment of forces, the muscle force $\left(\mathbf{F}_{\mathbf{m}}\right)$ of the five participants was calculated for $\boldsymbol{\alpha}_{1}=15^{\circ}$ and $\boldsymbol{\alpha}_{2}=20^{\circ}$. Distance $\mathbf{b}$ was assumed to be constant at $5 \mathrm{~cm}$ (Snijders et al. 2004). In order to normalise the EMG recordings, the "maximum voluntary isometric contraction" (MVIC) was also measured using manually applied resistance (Kumar and Mital 1996). The resulting calculated muscle forces, $\mathbf{F}_{\mathbf{m}}$, in Newton (N), EMG recordings in microvolt $(\mathrm{mV})$, MVIC recordings $(\mathrm{mV})$ and $\mathbf{F}_{\mathbf{m}}$ expressed in percentage MVIC (\% MVIC) can be found in Table 1 . Figure 2 shows muscle activity as a function of calculated muscle force for two bending angles.

\section{Study II}

Introduction of a chest support into the biomechanical model makes a univocal prediction of the related conditions even more difficult because $\mathbf{F}_{\text {support }}$ in Equation (2) is not known beforehand. It is an uncertain factor because it depends on how participants are leaning against the chest support. One possible way to assess the value of $\mathbf{F}_{\text {support }}$ is by comparing muscle activity with and without chest support. To this end, an assumption has to be made about the quantitative relation between muscle activity and force. Considering the relationship observed by Bendix et al. (1985) and Kumar and Mital (1996) a linear function between EMG recording (E) and calculated muscle force $\left(\mathbf{F}_{\mathbf{m}}\right)$ seems to be a good first-order approximation, or

$$
\mathbf{E}=\mathbf{m} \cdot \mathbf{F}_{\mathbf{m}}+\mathbf{n},
$$

Table 1. Calculated muscle force and EMG recordings, both in absolute values and in \%MVIC, for five participants in the condition without support and for two bending angles $\left(15^{\circ}\right.$ and $\left.20^{\circ}\right)$. Data have been taken from Albayrak et al. (2006a).

\begin{tabular}{|c|c|c|c|c|c|c|c|c|}
\hline \multirow[b]{2}{*}{ Participants } & \multirow[b]{2}{*}{ Body mass } & \multicolumn{2}{|c|}{ Muscle force $(\mathrm{N})$} & \multicolumn{2}{|c|}{ EMG $(\mathrm{mV})$} & \multirow[b]{2}{*}{ MVIC (mV) } & \multicolumn{2}{|c|}{$\%$ MVIC } \\
\hline & & $15^{\circ}$ & $20^{\circ}$ & $15^{\circ}$ & $20^{\circ}$ & & $15^{\circ}$ & $20^{\circ}$ \\
\hline $1 P_{5}(F)$ & $50 \mathrm{~kg}$ & 370 & 494 & 54 & 57 & 60 & 90 & 95 \\
\hline $2 \mathbf{P}_{50}(\mathrm{~F})$ & $70 \mathrm{~kg}$ & 580 & 767 & 33 & 34 & 60 & 55 & 56 \\
\hline $3 \mathbf{P}_{95}(\mathrm{~F})$ & $76 \mathrm{~kg}$ & 674 & 892 & 17 & 20 & 75 & 22 & 26 \\
\hline $4 P_{50}(M)$ & $80 \mathrm{~kg}$ & 670 & 885 & 36 & 39 & 86 & 41 & 45 \\
\hline $5 \mathrm{P}_{95}(\mathrm{M})$ & $90 \mathrm{~kg}$ & 865 & 1144 & 26 & 31 & 92 & 28 & 33 \\
\hline
\end{tabular}

$\mathrm{F}=$ female, $\mathrm{M}=$ male 


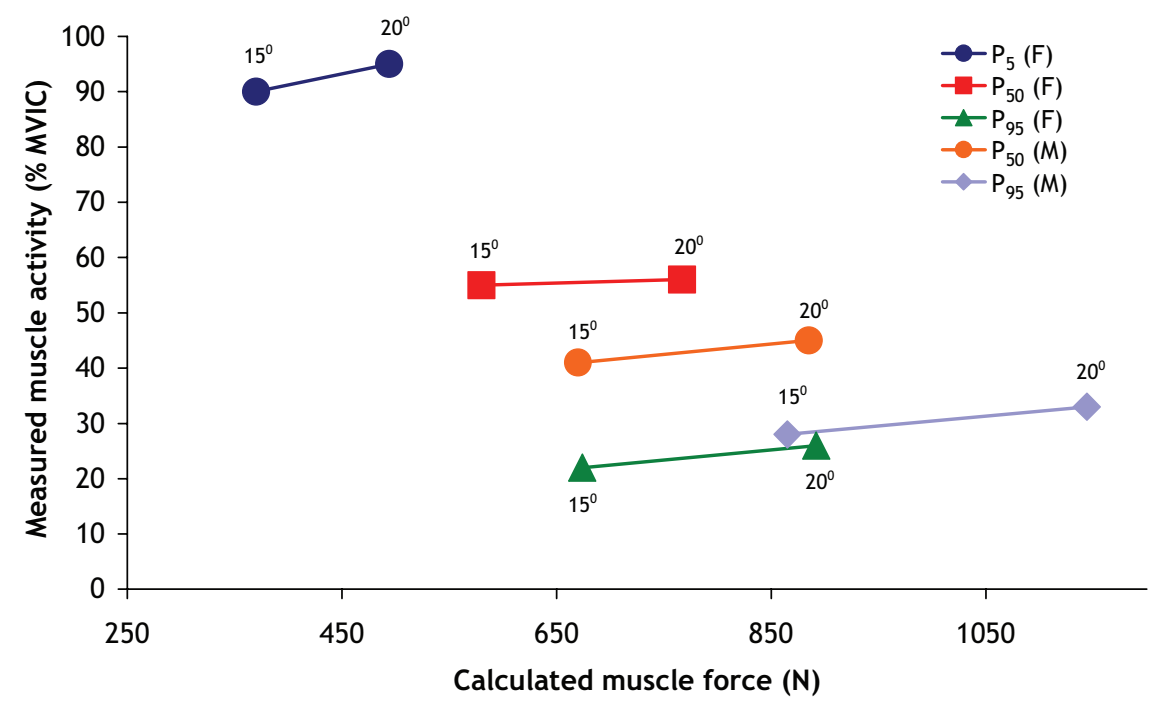

Figure 2. Measured EMG recording, expressed in \% MVIC, as a function of muscle force in the lower back calculated according to the biomechanical model without support (Equation (1)) for two bending angles. The characteristics of the subjects are presented in Table 1.

where $\mathbf{m}$ and $\mathbf{n}$ are constants. Then, the following relation holds for the condition without support

$$
\mathbf{E}_{\mathbf{W O S}}=\mathbf{m} \cdot \mathbf{F}_{\mathrm{g}} \cdot(\mathbf{a} / \mathbf{b})+\mathbf{n} \text {, }
$$

and the following relation for the condition with support

$$
\mathbf{E}_{\mathrm{WS}}=\mathbf{m} \cdot \mathbf{F}_{\mathrm{g}} \cdot(\mathbf{a} / \mathbf{b}) \mathbf{m} \cdot \mathbf{F}_{\text {support }} \cdot(\mathbf{c} / \mathbf{b})+\mathbf{n}
$$

with $\mathbf{E}_{\mathbf{W O S}}$ and $\mathbf{E}_{\mathbf{W S}}$ being actual EMG recordings under similar conditions (bending angle and height of the support). Then $\mathbf{F}_{\text {support }}$ can be estimated by subtracting Equation (4) from Equation (5) resulting in the following expression:

$$
\mathbf{F}_{\text {support }}=\left(\mathbf{E}_{\mathrm{WOS}}-\mathbf{E}_{\mathrm{WS}}\right) \cdot \mathbf{b} /(\mathbf{m} \cdot \mathbf{c}) .
$$

\section{Participants}

In total sixteen healthy volunteers were participating in this study. Nine of the participants were females (age $26.3 \pm$ $2.4 \mathrm{yr}$ ) and 7, males (age $28.8 \pm 5.3 \mathrm{yr}$ ). The percentiles and body mass of the participants are shown in Table 2.

The participants were selected regarding their anthropometric characteristics for guarantee enough variation between subjects.

\section{Protocol}

A prototype of a chest support was used during the experiment. The chest support was adjustable in height and bending angle. The chest support was revolving on its vertical axis (Figure 3).

The angle of the chest support was adjusted by the researcher using a digital protractor type 106 ES (Mahr, Göttingen, Germany). The participants were positioned in front of the chest support placing their feet in the area on the floor that was marked with tape. Without using the chest support the participants were asked to bend forward. The angle of their upper body was measured by the researcher by placing the digital protractor on their back.

When using the chest support, the participants were asked to lean against the chest support of which the bending

\begin{tabular}{|c|c|}
\hline Participants & Body mass \\
\hline $1 P_{3}(F)$ & $50 \mathrm{~kg}$ \\
\hline $2 P_{8}(F)$ & $57 \mathrm{~kg}$ \\
\hline $3 \mathbf{P}_{13}(\mathrm{~F})$ & $55 \mathrm{~kg}$ \\
\hline $4 P_{24}(F)$ & $62 \mathrm{~kg}$ \\
\hline $5 \mathbf{P}_{45}(\mathrm{~F})$ & $60 \mathrm{~kg}$ \\
\hline $6 P_{57}(\mathrm{~F})$ & $71 \mathrm{~kg}$ \\
\hline $7 \mathbf{P}_{74}(\mathrm{~F})$ & $92 \mathrm{~kg}$ \\
\hline $8 P_{79}(F)$ & $67 \mathrm{~kg}$ \\
\hline $9 \mathbf{P}_{89}(\mathrm{~F})$ & $56 \mathrm{~kg}$ \\
\hline $10 P_{7}(M)$ & $79 \mathrm{~kg}$ \\
\hline $11 P_{11}(\mathrm{M})$ & $73 \mathrm{~kg}$ \\
\hline $12 P_{17}(M)$ & $68 \mathrm{~kg}$ \\
\hline $13 P_{18}(\mathrm{M})$ & $57 \mathrm{~kg}$ \\
\hline $14 P_{23}(\mathrm{M})$ & $76 \mathrm{~kg}$ \\
\hline $15 P_{45}(M)$ & $80 \mathrm{~kg}$ \\
\hline $16 P_{98}(\mathrm{M})$ & $97 \mathrm{~kg}$ \\
\hline
\end{tabular}

Table 2. The calculated percentiles and body mass of the participants.

Percentiles are calculated using the dined table (Molenbroek 2004). 


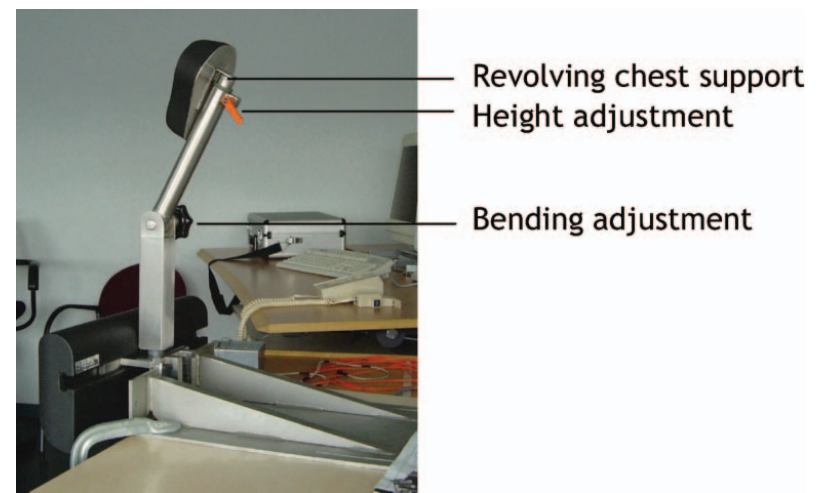

Figure 3. Experimental set-up chest support.

angle was adjusted in advance. Again the bending angle of the upper body of the participants was measured using the digital protractor. The participants could give feedback on the experienced comfort.

The muscle activities of the participants were measured by means of EMG recording while they were bending forward with their hands in their waists with and without using the chest support. All participants followed the same protocol (P) consisting of thirteen conditions. Each condition was performed during $10 \mathrm{~s}$, followed by $15 \mathrm{~s}$ rest. Each condition was repeated three times and the average value was determined. The conditions of the protocol were:

P1: relaxed standing

P2: bending forward without support at angle $\alpha_{1}$

P3: bending forward without support at angle $\alpha_{2}$

P4: bending forward without support at angle $\alpha_{3}$

P5: bending forward without support at angle $\alpha_{4}$

P6: bending forward with support at angle $\alpha_{1}$ and height $\mathbf{h}_{1}$

P7: bending forward with support at angle $\alpha_{1}$ and height $\mathbf{h}_{2}$

P8: bending forward with support at angle $\alpha_{2}$ and height $\mathbf{h}_{2}$

P9: bending forward with support at angle $\alpha_{2}$ and height $\mathbf{h}_{1}$

P10: bending forward with support at angle $\alpha_{3}$ and height $\mathbf{h}_{1}$

P11: bending forward with support at angle $\alpha_{3}$ and height $\mathbf{h}_{2}$

P12: bending forward with support at angle $\alpha_{4}$ and height $\mathbf{h}_{2}$

P13: bending forward with support at angle $\boldsymbol{\alpha}_{4}$ and height $\mathbf{h}_{1}$

Height $\mathbf{h}_{1}$ was defined as $0.8 \times$ shoulder height and $\mathbf{h}_{2}$ as $0.9 \times$ shoulder height. Angles $\boldsymbol{\alpha}_{1}, \boldsymbol{\alpha}_{2}, \boldsymbol{\alpha}_{3}, \boldsymbol{\alpha}_{4}$ were $15^{\circ}$, $20^{\circ} 30^{\circ}, 40^{\circ}$ respectively.

\section{EMG recording}

A selected muscle group was examined in the lab by means of EMG recording. In order to normalise the data for comparison, the MVIC was also measured (Kumar and Mital 1996). Normalising the data according the MVIC allows analysis between subjects and muscles. MVIC's were all obtained with manually applied resistance. Prior to attaching the electrodes, the skin was grated and then cleaned with alcohol. A reference electrode was placed on the left wrist. For the MVIC and EMG recordings, a portable physiological measurement system, type Porti 5-16/ASD of TMS International B.V. (Enschede, The Nederlands) was used. The $\mathrm{Ag} / \mathrm{AgCl}$ surface electrodes with recessed pre-gelled (hydrogel) elements (GE Medical Systems Accessories Europe, Hoevelaken) were used to collect the MVIC and EMG signals. The raw EMG signals (DC frequency, $\sim 2 \mathrm{kHz}$ ) were processed electronically with a sample rate of 1000 $\mathrm{Hz}$, and the cut-off frequency was $10 \pm 200 \mathrm{~Hz}$.

The following muscles were examined:

- $\mathrm{m}$. erector spinae (lower back muscles, both sides at about $2 \mathrm{~cm}$ from the midline at the level of $\mathrm{L}_{5}-\mathrm{S}_{1}$, Snijders et al. 1998)

- m. rectus abdominis (abdominal muscle, $2 \mathrm{~cm}$ lateral to midline at the level of the umbilicus, Snijders et al. 1998)

- $\mathrm{m}$. semitendinosus (hamstring in the right leg)

- m. gastrocnemius (calf muscle, caput mediale in the right leg)

The software program SPSS 12.0.1 for Windows is used to analyse the results statistically.

\section{Results}

\section{EMG recording: general}

Figure 4 shows the results of the EMG recording averaged across all participants as a function of bending angle for each muscle separately.

On average the muscle activity during relaxed standing is $\sim 6 \%$ MVIC. The minimal muscle activity for all measured muscles except for $\mathrm{m}$. gastrocnemius is during relaxed standing. During bending forward without support, in general muscle activity increases proportionally with the bending angle. The only exception is $\mathrm{m}$. rectus abdominis where the muscle activity stays at the relaxed standing level. The usage of the chest support reduces muscle activity for all angles with again the exception of $\mathrm{m}$. rectus abdominis where the muscle activity tends to increase.

To analyse the general findings statistically, a three-way full factorial within subjects repeated measures ANOVA was conducted with main effects: muscle $(5) \times$ angle $(4) \times$ height ( 3 ; without support and with support at two heights). The results of this analysis are shown in Table 3. All the main effects and interaction effects turn out to be significant. 

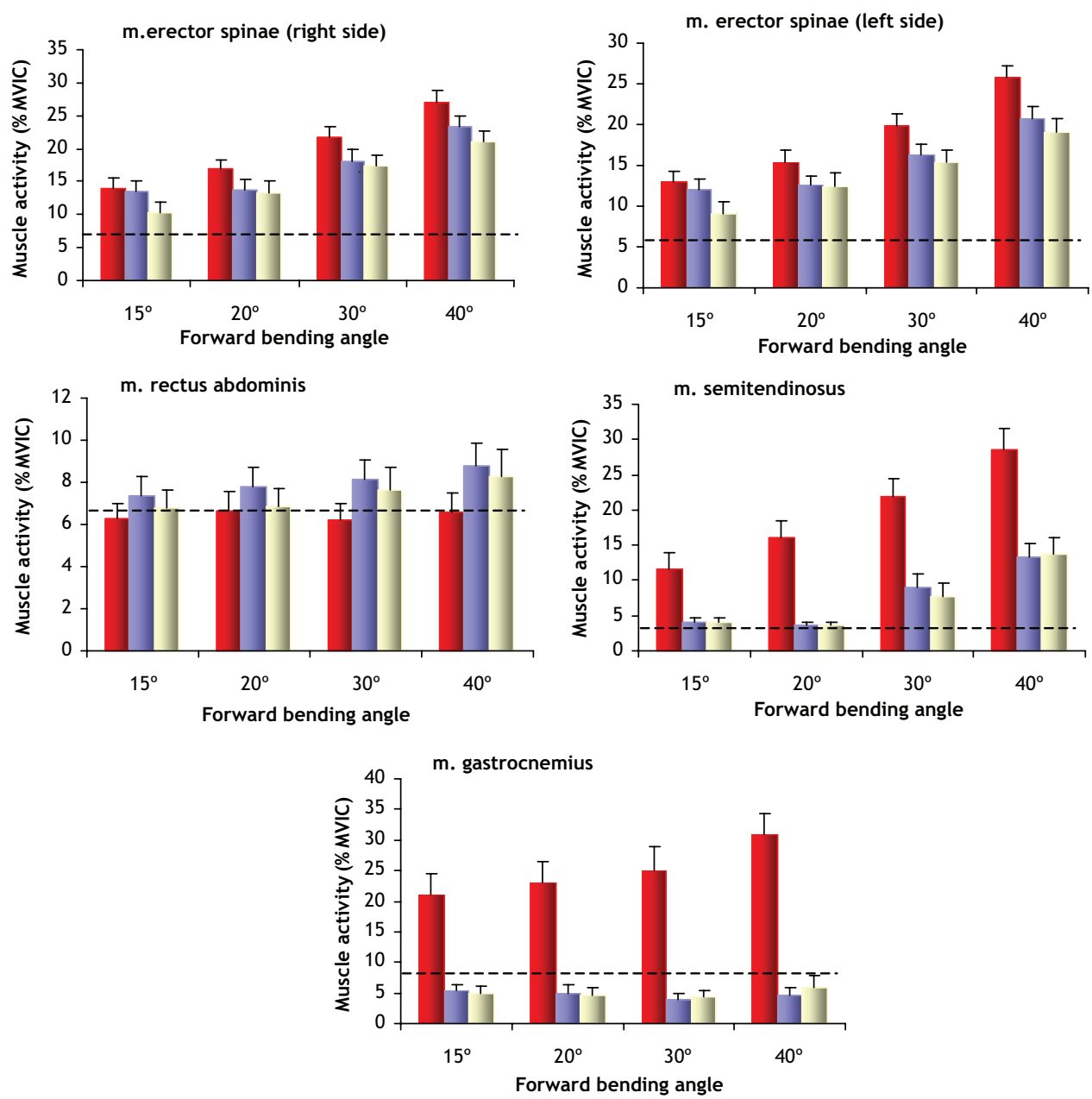

Bending forward without support

Bending forward with support height $\mathrm{h}_{1}$

a Bending forward with support height $h_{2}$

Relaxed standing

Figure 4. Results of EMG recording averaged across all participants. Note that scales for muscle activity differ between muscles.

\section{Main effects}

Regarding the main effect muscle, both sides of $\mathrm{m}$. erector spinae show the most muscle activity. The lowest muscle activity was measured at $\mathrm{m}$. rectus abdominis, and the muscle activity of $\mathrm{m}$. semitendinosus and $\mathrm{m}$. gastrocnemius was in the same range. The activity of the lower back muscles differs significantly from that of the $\mathrm{m}$. rectus abdominis. Regarding the main effect height, the muscle activity during bending forward without support is significantly higher than with support. Although the muscle activity during bending

Table 3. Results of full factorial ANOVA within subjects repeated measures (Field 2005).

\begin{tabular}{llllrrr}
\hline \multicolumn{1}{c}{ Source } & df & df error & Mean square & F & Significance \\
\hline Main effect & Muscle & 4.00 & 60 & 3175.83 & 11.49 & .000 \\
& Height & 1.16 & 17.47 & 10796.24 & 44.70 & .000 \\
& Angle & 1.87 & 28.11 & 4390.17 & 79.82 & .000 \\
Interaction & Muscle $*$ Height & 2.04 & 30.62 & 6011.18 & 26.12 & .000 \\
& Muscle $*$ Angle & 3.94 & 59.23 & 767.07 & 11.84 & .000 \\
& Height $*$ Angle & 2.95 & 44.25 & 204.66 & 6.98 & .001 \\
& Muscle $*$ Height $*$ Angle & 5.96 & 89.52 & 92.56 & 2.57 & .024 \\
\hline
\end{tabular}


forward with support on height $\mathbf{h}_{\mathbf{2}}$ was systematically lower than on height $\mathbf{h}_{\mathbf{1}}$, this difference was non-significant. Regarding the main effect angle, the muscle activity increases systematically with the bending angle. The muscle activity at the four angles differs significantly from each other.

\section{Interaction effects}

The interaction between muscle and height is mainly caused by the different ways the muscles react on the usage of the support. The activity of $\mathrm{m}$. erector spinae at both sides reduces gradually to a value of $77 \%$ of the activity without support; this value is measured for height $\mathbf{h}_{\mathbf{2}}$. Much larger reductions have been found for the leg muscles towards $37 \%$ for $\mathrm{m}$. semitendinosus and $19 \%$ for $\mathrm{m}$. gastrocnemius. The activity of the m. rectus abdominis increased by $25 \%$. The interaction between muscle and angle can be attributed to the angle at which the different muscles recruited: both sides of $\mathrm{m}$. erector spinae at $15^{\circ}$, the $\mathrm{m}$. semitendinosus at $20^{\circ}$ and the m. gastrocnemius at $30^{\circ}$. The activity of $\mathrm{m}$. rectus abdominis hardly changes with the angle. Finally, the interaction between height and angle can be attributed to increasing difference between muscle activity without support and with support as a function of angle.

\section{EMG recording: per muscle}

Table 4 shows the results of two-way full factorial within subjects repeated measures ANOVA per muscle with main effects angle (4) and height (3).

The measured muscle activity of $\mathrm{m}$. erector spinae at both sides shows a similar pattern (Figure 4). The minimal muscle activity at both sides is during relaxed standing. The significant interaction effect is caused by the finding that at $15^{\circ}$ the muscle activity without support equals almost the activity with support at height $\mathbf{h}_{\mathbf{1}}$, whereas at the other angles the main reduction in muscle activity occurred between these two conditions.

The measured activity of $\mathrm{m}$. rectus abdominis remains at the level of relaxed standing for all angles when no support was used. Contrary to the other muscles, the activity increases when the support is used. For all angles the activity at height $\mathbf{h}_{\mathbf{1}}$ is higher than that at height $\mathbf{h}_{\mathbf{2}}$. There was no interaction effect.

The minimal activity of $\mathrm{m}$. semitendinosus is during relaxed standing and at conditions with support at $15^{\circ}$ and $20^{\circ}$. Without support, muscle activity increases proportionally with the bending angle. With support the muscle activity is recruited starting from $30^{\circ}$. The significant interaction effect between height and angle can be attributed to this difference in the angle at which the muscle is recruited in the conditions with and without support.

The activity of $\mathrm{m}$. gastrocnemius increases with the bending angle during bending forward without support. Surprisingly, the muscle activity during all conditions is
Table 4. Results of full factorial ANOVA within subjects repeated measures per muscle (Field 2005).

\begin{tabular}{|c|c|c|c|c|c|}
\hline Source & df & df error & Mean square & $\mathrm{F}$ & Sig. \\
\hline \multicolumn{6}{|c|}{ m. erector spinae (right side) } \\
\hline \multicolumn{6}{|l|}{ Main effect } \\
\hline Height & 1.43 & 21.49 & 437.19 & 13.34 & .001 \\
\hline Angle & 1.63 & 24.48 & 2178.93 & 59.7 & .000 \\
\hline \multicolumn{6}{|l|}{ Interaction } \\
\hline Height $*$ Angle & 3.58 & 53.83 & 25.85 & 2.82 & .038 \\
\hline \multicolumn{6}{|c|}{ m. erector spinae (left side) } \\
\hline \multicolumn{6}{|l|}{ Main effect } \\
\hline Height & 2 & 30 & 337.09 & 23.57 & .000 \\
\hline Angle & 1.31 & 19.66 & 2343.65 & 49.45 & .000 \\
\hline \multicolumn{6}{|l|}{ Interaction } \\
\hline Height $*$ Angle & 6 & 90 & 18.65 & 5.34 & .000 \\
\hline \multicolumn{6}{|l|}{ m. rectus abdominis } \\
\hline \multicolumn{6}{|l|}{ Main effect } \\
\hline Height & 2 & 30 & 40.79 & 7.65 & .002 \\
\hline Angle & 1.57 & 23.57 & 19.21 & 6.01 & .012 \\
\hline \multicolumn{6}{|l|}{ Interaction } \\
\hline Height $*$ Angle & 2.35 & 35.33 & 5.66 & 1.66 & .201 \\
\hline \multicolumn{6}{|l|}{ m. semitendinosus } \\
\hline \multicolumn{6}{|l|}{ Main effect } \\
\hline Height & 1.13 & 16.98 & 5500.89 & 28.54 & .000 \\
\hline Angle & 1.66 & 25.02 & 2554.54 & 37.74 & .000 \\
\hline \multicolumn{6}{|l|}{ Interaction } \\
\hline Height $*$ Angle & 2.47 & 37.08 & 146.99 & 3.16 & .044 \\
\hline \multicolumn{6}{|l|}{ m. gastrocnemius } \\
\hline \multicolumn{6}{|l|}{ Main effect } \\
\hline Height & 1.03 & 15.47 & 16711.36 & 38.58 & .000 \\
\hline Angle & 1.63 & 24.56 & 205.37 & 2.82 & .088 \\
\hline \multicolumn{6}{|l|}{ Interaction } \\
\hline Height $*$ Angle & 2.65 & 39.84 & 216.39 & 4.61 & .009 \\
\hline
\end{tabular}

below the activity level at relaxed standing. The interaction is caused by the fact that activity with support does not change with angle whereas activity without support increases as a function of the angle.

\section{EMG recording: individual level}

A hierarchical cluster analysis was conducted on the EMG recording of the five muscles to identify users with similar patterns in muscle activity. This resulted in three clusters. The average data of these clusters can be found in Figure 5. Cluster 1 represents the largest group consisting of 13 participants. The three remaining participants had a deviant pattern and were divided in Cluster 2 (two participants) and Cluster 3 (one participant). In Figure 5 the EMG recordings of the measured muscles are represented in two parts with the left part representing the conditions during relaxed standing (RS) and without support and the right part, the conditions using the chest support (WS = with support). The measurements for the two different heights belonging to the same bending angle were averaged.

The main difference between Cluster 1 and Cluster 2 in the condition without support is the activity of the two 

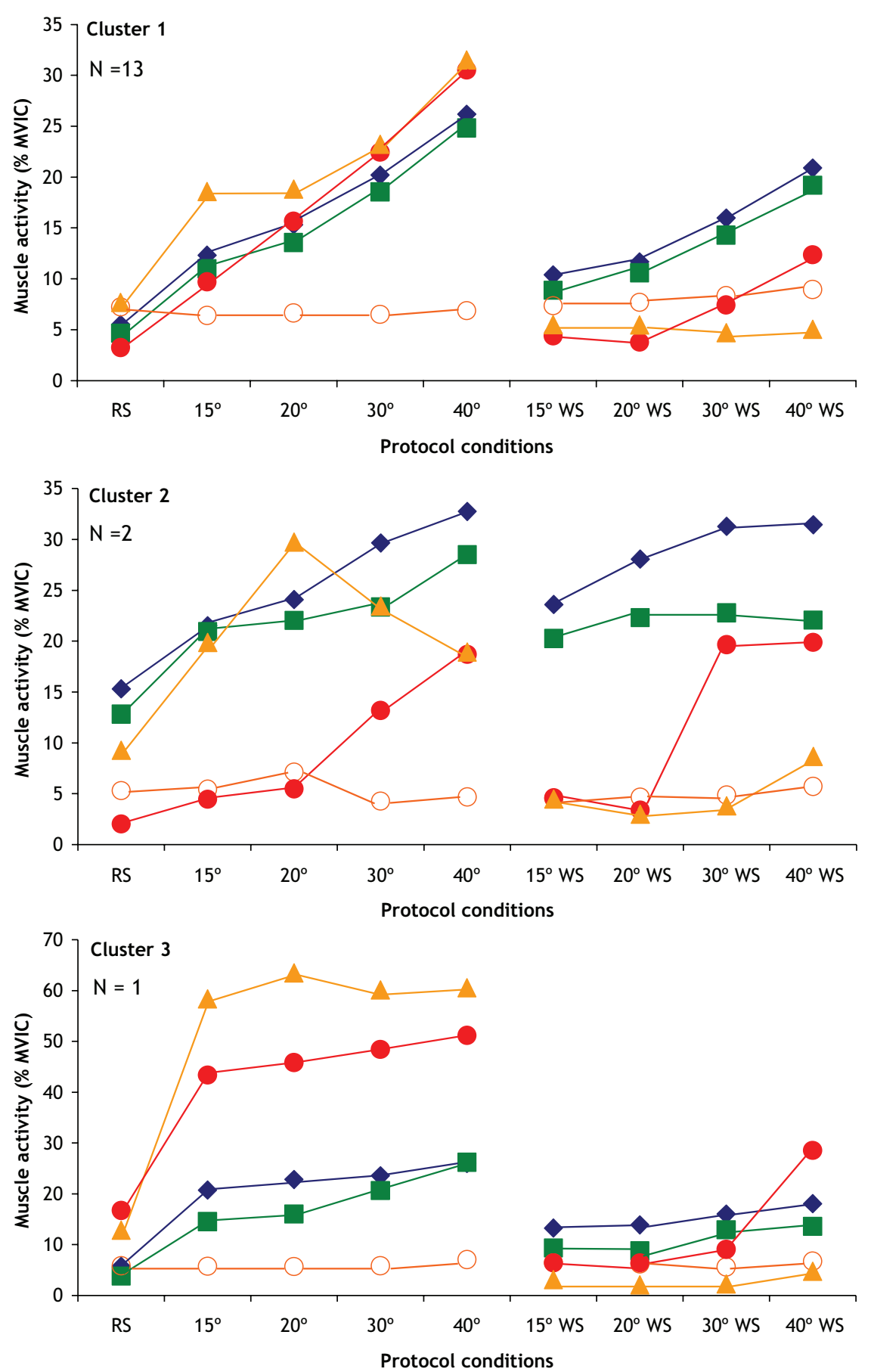

$\checkmark$ m. erector spinae (right side)

- m. erector spinae (left side)

$-\mathrm{m}$. rectus abdominis

- m. semitendinosus

$\triangle \mathrm{m}$. gastrocnemius

$\mathrm{RS}=$ Relaxed standing

WS $=$ With support

Figure 5. EMG recording of the measured muscles per protocol condition. Left-hand panel: conditions during relaxed standing (RS). Right-hand panel: conditions using the chest support (WS = with support). The measurements for the two different heights belonging to the same bending angle were averaged. 


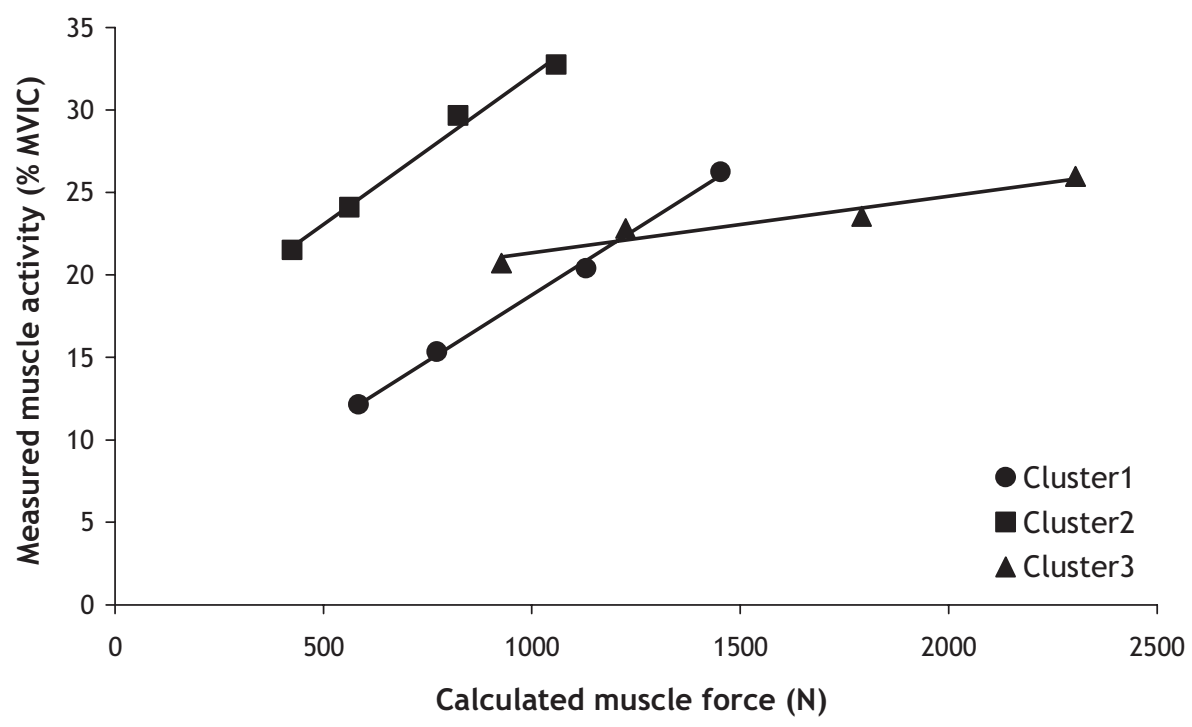

Figure 6. Measured EMG recording, expressed in \% MVIC, as a function of muscle force in the lower back calculated according to the biomechanical model without support (Equation (1)) for four bending angles. The data for Cluster 1 and 2 are the averages across participants. The equations for the fitted regression lines are:

Cluster 1: $\mathrm{EMG}=2.8(\mathrm{SD} \pm 6.1)+0.016 \mathbf{F}_{\mathbf{m}}(\mathrm{SD} \pm 0.009)\left(\right.$ Adjusted $\left.\mathrm{R}^{2}=.99\right)$

Cluster 2: $\mathrm{EMG}=13.98(\mathrm{SD} \pm 7.53)+0.017 \mathbf{F}_{\mathbf{m}}(\mathrm{SD} \pm 0.006)\left(\right.$ Adjusted $\left.\mathrm{R}^{2}=.99\right)$

Cluster 3: $\mathrm{EMG}=17.91+0.003 \mathbf{F}_{\mathbf{m}}$ (Adjusted $\mathrm{R}^{2}=.93$ )

leg muscles. In Cluster 1 the activities in these muscles increase systematically with the bending angle. In Cluster 2 , only the $\mathrm{m}$. gastrocnemius is increasingly active at $15^{\circ}$ and $20^{\circ}$ and decreases in activity at $30^{\circ}$ and $40^{\circ}$, while at the same time the activity of $\mathrm{m}$. semitendinosus increases. Most characteristic aspect of Cluster 3 is the high activity of the two leg muscles with respect to the relatively low activity of the lower back muscles.

The main difference between Cluster 1 and Cluster 2 in the condition with support is that the effect of the chest support on the lower back muscle activity is relatively small in cluster 2. Furthermore, the sudden increase of $\mathrm{m}$. semitendinosus for Cluster 2 at $30^{\circ}$ is remarkable. Finally, in Cluster 3 all the muscle activities seem hardly to deviate from that at relaxed standing except for $40^{\circ}$.

\section{EMG recording and the biomechanical model}

Figure 6 shows, per cluster, the measured EMG recording, expressed in \% MVIC, as a function of muscle force in the lower back (m. erector spinae (right side)) calculated according to the biomechanical model without support for four bending angles.

In each cluster the averaged data appear to lie on a straight line as conformed by the linear regressions. Furthermore Figure 6 shows that the data of the different clusters do not overlap. Data of Cluster 1 and 2 show a parallel shift. The characteristic for the participant of Cluster 3 is the little variation of muscle activity with respect to the model prediction. The main suggestion from this figure is that each overall pattern of muscle activity needed for balancing the body results in a different relation between measured muscle activity and model prediction for lower back muscle.

\section{Estimated supporting force}

To assess the degree of use of the chest support by the participants, an estimation of the supporting force was made by subtracting the muscle activity without support from the muscle activity with support. According to Equation (6) this should result in an estimation of the $\mathbf{F}_{\text {support }}$ besides a multiplication factor. This factor was determined from the linear regression in Figure 6 (parameter $\mathbf{m}$ ) and the height of the chest support (parameter c) while the value of parameter $\mathbf{b}$ was fixed at $5 \mathrm{~cm}$. Figure 7 denotes the resulting $\mathbf{F}_{\text {support }}$ as a function of the bending angle $\boldsymbol{\alpha}$. In addition Figure 7 shows the outcome of the linear regression per cluster.

Cluster 1 (representing the majority of the participants) and Cluster 2 show a similar pattern in that the estimated supporting force increases linearly with bending angle. The difference between these clusters is that for Cluster $1 \mathbf{F}_{\text {support }}$ is always positive while for Cluster 2 it is mostly negative becoming neutral at $40^{\circ}$. It seems that for the participant of cluster 3, the estimated $\mathbf{F}_{\text {support }}$ is independent of the bending angle, and the value of $\mathbf{F}_{\text {support }}$ is significantly higher than that of the other participants. 


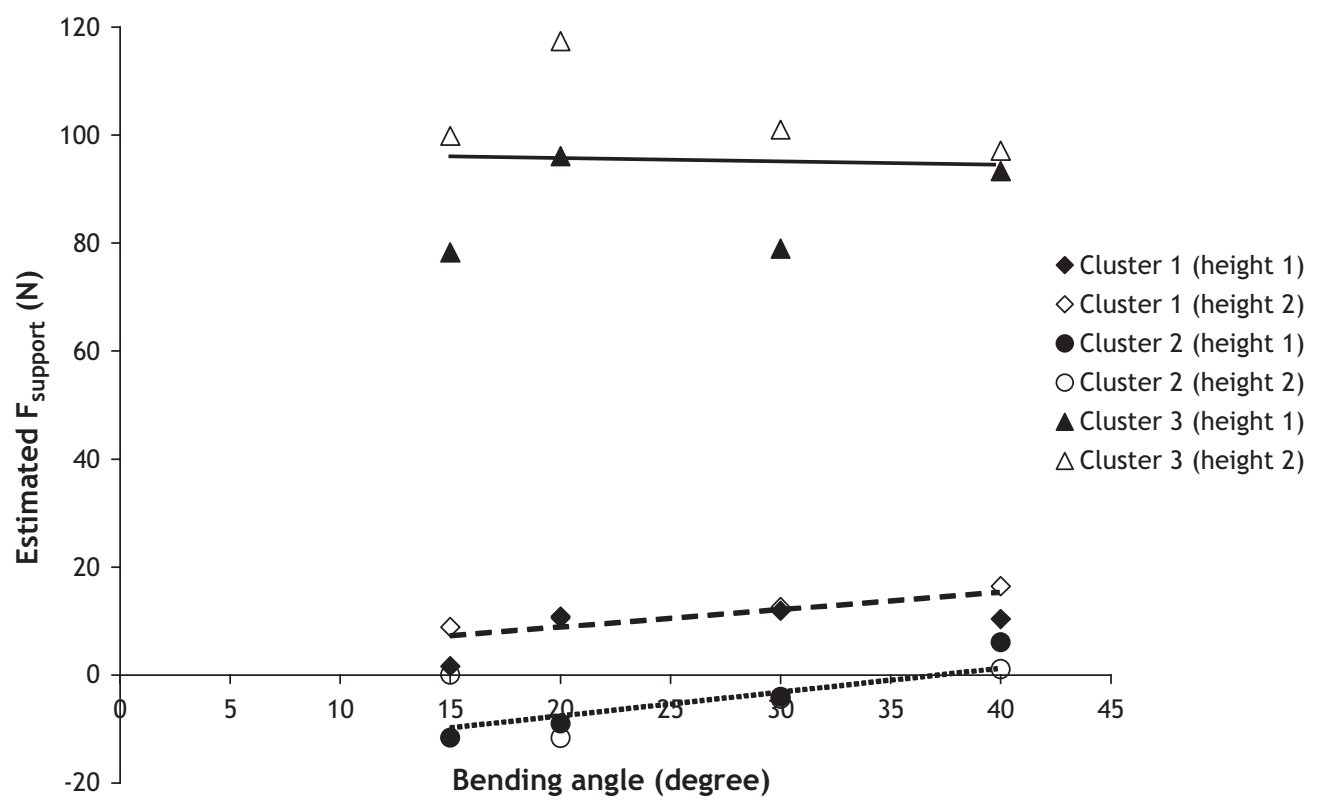

Figure 7. Estimated supporting force per cluster and height at corresponding bending angles (Equation (6)). The equations for the fitted regression lines are:

Cluster 1: $\mathbf{F}_{\text {support }}=2.92+0.28 \boldsymbol{\alpha}\left(\right.$ Adjusted $\left.\mathrm{R}^{2}=.48\right)$

Cluster 2: $\mathbf{F}_{\text {support }}=-15.79+0.44 \alpha\left(\right.$ Adjusted $\left.\mathrm{R}^{2}=.51\right)$

Cluster 3: $\mathbf{F}_{\text {support }}=96.91-0.06 \boldsymbol{\alpha}\left(\right.$ Adjusted $\left.\mathrm{R}^{2}=.003\right)$

\section{Discussion}

The aim of the present study is to investigate how subjects make use of a chest support in general and on individual level and to study the influence of the chest support on the muscle activity during bending forward. In this way a possible relation between $\mathbf{F}_{\text {support }}$ and the kind of balancing strategy a person is adopting in the current set-up might be established.

The results of our study imply that supporting the body by means of a chest support is effective in reducing muscle activity in the lower back and especially in leg muscles during bending forward. The significant interaction between height and angle in the measured muscles except for $\mathrm{m}$. rectus abdominis shows that both height and angle of the support affects the muscle activity. Optimal adjustment of height and angle is therefore essential for the desired effect of the chest support. Providing the chest support in professions with a similar head-bent and back-bent posture might reduce discomfort.

Considering the results per muscle, the activity of $\mathrm{m}$. erector spinae (both sides) during all conditions is highest compared with other measured muscles (Figure 4). This indicates that participants mainly use their lower back muscles during bending forward. It seems that up to $30^{\circ}$ the activity of the lower back muscles is sufficient to keep the upper body in balance. With increasing bending angle the $\mathrm{m}$. semitendinosus is recruited to support the lower back muscles. Using the chest support the muscle activ- ity of $\mathrm{m}$. gastrocnemius is even lower than during relaxed standing. Despite the different roles the four muscles are playing in balancing the body, the chest support is effective to reduce the activity of these muscles. An aberration appears at $\mathrm{m}$. rectus abdominis. The usage of the chest support is accompanied by increasing muscle activity of $m$. rectus abdominis. A possible explanation is that $\mathrm{m}$. rectus abdominis activity counteracts hollowing of the lumbar spine. According to Allison and Henry (2001) the predominant muscle action of the three most superficial abdominal muscles (the Obliques and Rectus) have been associated predominantly with trunk flexion activities with or without combined rotation. In this study, the role of the coactivation of the antagonists (three most superficial abdominal muscles) in spinal stability is also indicated (Allison and Henry 2001). One parameter with the potential to influence spinal mechanics and stability is intra-abdominal pressure (IAP). IAP has the potential to substantially unload the spine in standing and flexion tasks, a role that depends directly on the IAP magnitude and concurrent level of coactivity in abdominal muscles (Arjmand and Shirazi-Adl 2006). That is, IAP could indeed even increase the backmuscle forces when large co-activity is generated in the superficial abdominal muscles (the Obliques and Rectus) (Arjmand and Shirazi-Adl 2006). It seems that m. rectus abdominis plays a role in spinal stability. Correspondingly, Juker et al. (1998) advocated that muscles of the abdominal wall (rectus abdominis, external oblique, internal oblique, 
transverse abdominis) and psoas play a fundamental role in the normal functioning of the lumbar spine.

Although identifying individual differences was impossible, the cluster analysis distinguishes (Figure 5) three user groups regarding their balancing strategies. The participants of Cluster 1 can be mentioned as "sceptical users". During bending forward without chest support the muscle activity, except the $\mathrm{m}$. rectus abdominis, increases proportionally with the bending angle. The slight reduction of the muscle activity in the right part of the figure confirms the actual usage of the chest support. The pattern of behaviour of participants in Cluster 1 was characterised by simultaneously recruiting all the measured muscles except for $\mathrm{m}$. rectus abdominis. However, the limited decrease in the back muscle activity indicates that participants in this cluster are sceptical about the chest support whereby they partially manage the balancing of the upper body by themselves. The little variation of the estimated supporting force within Cluster 1 suggests a limited use of the chest support. However, the reduced muscle activity in the leg muscles indicates that the subjects of Cluster 1 are standing relaxed during the use of the chest support.

The second cluster can be identified as "non-trusters". During bending forward without support, primarily the $\mathrm{m}$. erector spinae (both sides) and the $\mathrm{m}$. gastrocnemius are active to keep the upper body in balance. It is obvious that the participants in this cluster change their balance strategy after a bending angle of $20^{\circ}$. Hereby a reduction of the $\mathrm{m}$. gastrocnemius is accompanied by an increased activity of the m. semitendinosus. Focusing on the part with support it becomes clear that the usage of the chest support is not optimal. Reduction of muscle activity, especially in the $\mathrm{m}$. erector spinae, is minimal. Even after reaching the bending angle of $20^{\circ}$, the activity of the $\mathrm{m}$. semitendinosus increases dramatically to keep the upper body in balance. The participants of Cluster 2 primarily used the $\mathrm{m}$. erector spinae during bending forward. However, recruiting of $\mathrm{m}$. semitendinosus after reaching the bending angle of $20^{\circ}$ indicates the necessity of additional muscle activity at increasing bending angles to keep the upper body in balance. The minimal reduction of muscle activity indicates that participants of this cluster entirely is trust the chest support. The negative value of the estimated supporting force indicates that the two participants of Cluster 2 hardly made use of the chest support.

The participant in the last cluster can be classified as "fully truster". The participant in this cluster keeps the upper body in balance principally with the $\mathrm{m}$. semitendinosus and $\mathrm{m}$. gastrocnemius during bending forward without support. During bending forward with support the muscle activity in all the muscles is decreased dramatically, which shows that the participant trust the chest support totally by leaning against it. An aberration of $\mathrm{m}$. semitendinosus occurs during bending forward with support at $40^{\circ}$. However, recruiting of this muscle is not significant for the behaviour of this participant since the muscle activity is still below the activity without support. With regard to simultaneous recruiting of muscles, Cluster 3 shows similarities with cluster 1. However, in Cluster 3 the activity of $\mathrm{m}$. erector spinae is clearly lower than the activity of the leg muscles, indicating the balancing role of the leg muscles during bending forward. Apparently this participant makes strong use of the chest support, since the estimated supporting force is significantly higher than that of the other participants.

The pattern of muscle activity of the identified clusters in the current study is in agreement with the findings of Winter (1995). Since the activity of the $\mathrm{m}$. gastrocnemius is the highest compared with other muscles during relaxed standing (Figure 4), the ankle strategy applies in quiet stance. The participants of Cluster 1 were defined as "sceptical users". Regarding the simultaneously recruiting of the lower back and leg muscles and limited use of the chest support, it is clear that the participants of Cluster 1 use the combined strategy for balance. Cluster 2 was characterised as "nontrusters". It seems that the two participants of this cluster hardly made use of the chest support and adopting the hip strategy since primarily the $\mathrm{m}$. erector spinae is involved for balancing. Conversely, the participant of Cluster 3, defined as the "fully truster", balances the body using the ankle strategy, since mainly the leg muscles are recruited.

The muscle activity as a function of calculated muscle force shows that the observed linearity on the average level also holds on the individual level. After analysis of the individual data, no systematic effect of $p$-value (comprising body length) on the relation between muscle activity and model prediction could be observed contrary to what was found in the previous study (Figure 2). Furthermore the range of measured and predicted values between individuals was rather small. No systematic differences between males and females were found.

\section{Conclusions}

Supporting the body by means of a chest support shows a systematic reduction of muscle activity in the lower back and leg muscles. Identifying three user groups with corresponding balance strategies indicate the variety within the pattern of behaviour of individuals. Measuring the activity of multiply muscles by means of EMG recording is needed to identify the pattern of behaviour of users. Although the experimental conditions were the same, humans tend to follow different balancing strategies. An advice for product designers is therefore that it is valuable to take the anthropometric characteristics and the conditions of the users into account to meet their specific needs. However, do not consider only the anthropometry of individuals during product development for supporting purposes, but also offer the possibility to alter the posture and preferably do not constrain the user into taking a certain body posture. 


\section{Acknowledgements}

The authors would like to acknowledge the contribution of the company "Professional Health Design" directed by M.A. van Veelen for providing the prototype of the chest support for this study.

\section{References}

Albayrak A, van Veelen MA, Prins J, Snijders CJ, de Ridder H, Kazemier G. 2006a. Reducing muscle activity of the surgeon during surgical procedures. Meeting Diversity in Ergonomics, 16th World Congress on Ergonomics, Maastricht, The Netherlands, Elsevier Ltd.

Albayrak A, van Veelen MA, Prins J, Snijders CJ, de Ridder H, Kazemier G. 2006b. Rugbelasting bij chirurgen tijdens operaties: het effect van lichaamsondersteuning. Tijdschrift voor Ergonomie. 31:10-19.

Albayrak A, van Veelen MA, Prins JF, Snijders CJ, de Ridder H, Kazemier G. 2007. A newly designed ergonomic body support for surgeons. Surg Endosc. 21:1835-1840.

Allison GT, Henry SM. 2001. Trunk muscle fatigue during a back extension task in standing. Man Ther. 6:221-228.

Arjmand N, Shirazi-Adl A. 2006. Role of intra-abdominal pressure in the unloading and stabilization of the human spine during static lifting tasks. Eur Spine J. 15:12651275.

Arjmand N, Shirazi-Adl A. 2005. Model and in vivo studies on human trunk load partitioning and stability in isometric forward flexions. J Biomech. 39:510-521.
Bendix T, Krohn L, Jessen F, Aaras A. 1985. Trunk posture and trapezius muscle load while working in standing, supportedstanding and sitting postions. Spine. 10:433-439.

Field A. 2005. Discovering Statistics Using SPSS. London (UK): SAGE publications Ltd.

Granata KP, Marras WS. 1995. An EMG-Assisted model of trunk loading during free-dynamic lifting. J Biomech. 28:13091317.

Juker D, McGill S, Kropf P, Steffen T. 1998. Quantitative intramuscular myoelectric activity of lumbar portions of psoas and the abdominal wall during a wide variety of tasks. Med Sci Sports Exerc. 30:301-310.

Kumar S, Mital A. 1996. Electromyography in Ergonomics. Padstow: Taylor \& Francis Ltd.

Molenbroek J. 2004. DINED table. [Internet] Available from http://www.dined.nl.

Rohlmann A, Claes LE, Bergmann G, Graichen F, Neef P, Wilke HJ. 2001. Comparison of intradiscal pressure and spinal fixator loads for different body positions and exercises. Ergonomics. 44:781-794.

Snijders CJ, Nordin M, Frankel VH. 2004. Biomechanica Van Het Spier-Skeletstelsel. Maarssen, The Netherland: Elsevier gezondheidszorg.

Snijders CJ, Ribbers MTLM, de Bakker HV, Stoeckart R, Stam HJ. 1998. EMG recordings of abdominal and back muscles in various standing postures: validation of a biomechanical model on sacroiliac joint stability. J Electromyogr Kines. 8:205-214.

Winter DA. 1995. Human balance and posture control during standing and walking. Gait Posture. 3:193-214. 

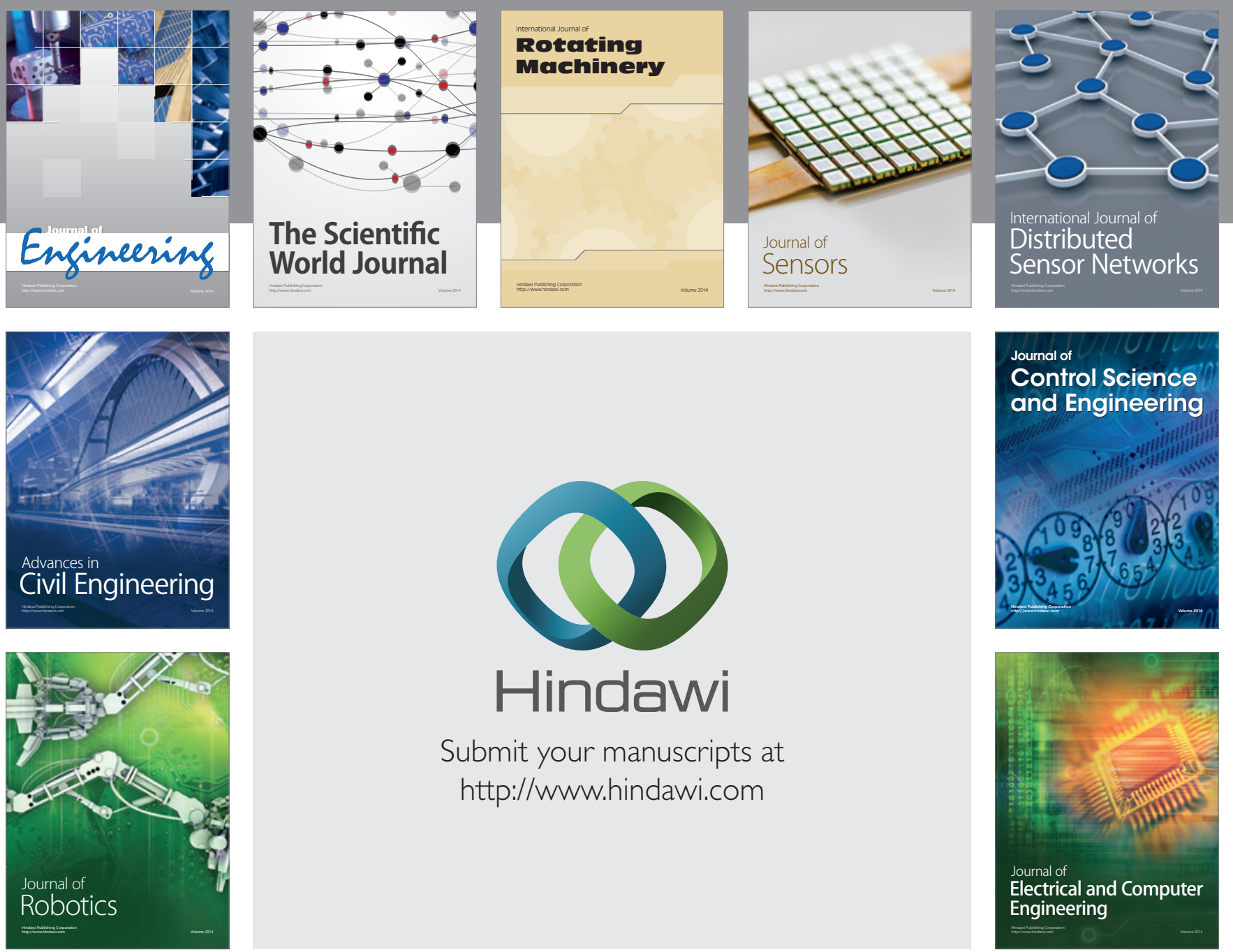

Submit your manuscripts at

http://www.hindawi.com
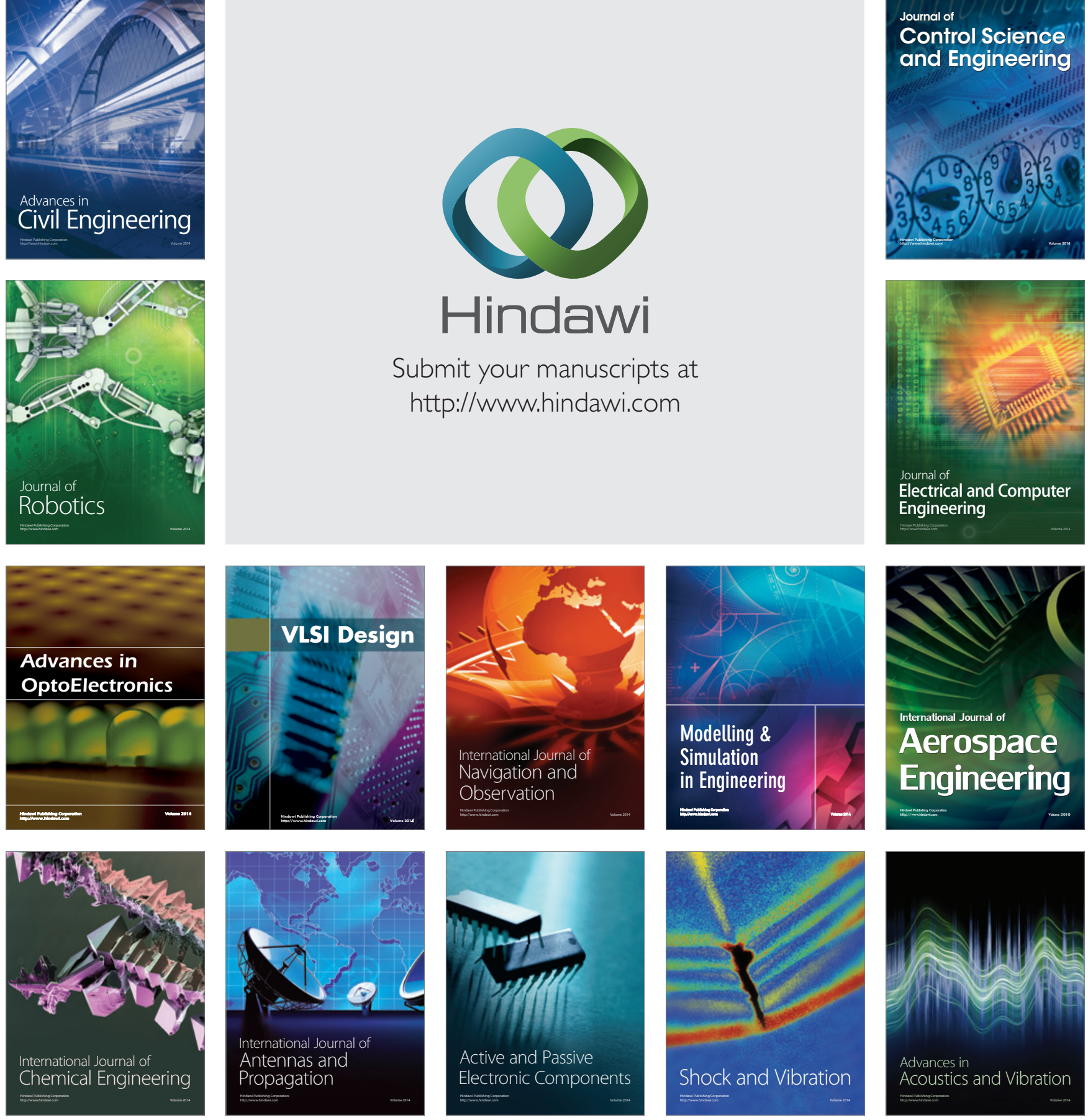